\title{
Laudatio zur Verleihung des René-König-Lehrbuchpreises
}

Martina Löw

Nun freue ich mich sehr, den René-König Lehrbuchpreis 2010 an

Ana Mijic, Sighard Neckel, Christian von Scheve und Monica Titton verleihen zu dürfen für den beim Campus Verlag erschienenen Band „Sternstunden der Soziologie“.

Dieses Buch ist ein Reader, versehen mit einer guten und sehr gut lesbaren Einleitung und 21 Texten von Autoren wie William Thomas, Georg Simmel, Robert Merton, Albert Hirschman, Heinrich Popitz und vielen anderen. Alle Einzeltexte sind mit einer sehr sorgfältigen Einleitung versehen worden. Insgesamt ist es ein unkonventionelles Lehrbuch, das Dilemmata und Fragen der Soziologie aufgreift, die nicht mit einer eindeutigen Lösung zu beantworten sind.

Die Kommission hält das Buch für eine gute Einführung in das soziologische Denken. Es ist eine Einführung, die Lust auf Soziologie macht, aufs Weiterdenken, Weiterfragen und Weiterlesen. Die Autoren und Autorinnen stehen für den Standpunkt, dass es nicht darauf ankommt, die Soziologie, in ihrer ganzen Breite zu vertreten oder die, wichtigsten' Soziologen angemessen zu vertreten, sondern darauf, dass Soziologieneulinge soziologisches Fragen lernen. Das Buch vermittelt die Art der Theorie-Konstruktionen, vor deren Hintergrund soziologisches Fragen möglich wird und mit der die Antworten plausibel diskutiert werden können.

Ich bitte nun die vier AutorInnen auf die Bühne. 